\title{
Peer Support Groups for Weight Loss
}

\section{Kelsey Ufholz ${ }^{1}$}

Published online: 22 August 2020

(C) The Author(s) 2020

\begin{abstract}
Purpose of Review Social support, especially from peers, has been found to contribute to successful weight loss and long-term weight loss maintenance. Peer support groups may represent a particularly effective intervention technique for weight loss. This review focuses upon peer support weight loss interventions with the objective of identifying common elements of successful programs.

Recent Findings Peer support interventions often consist of expert-led educational content, supplemented by peer-led activities or discussion. Peer groups may provide support to individuals who have little social support in their normal lives. Interventions are often designed for pre-existing groups, especially high-risk groups such as women from ethnic minorities. Men are underrepresented in weight loss programs and often perceive "dieting" as feminine. However, several peer programs for male sports fans have successfully resulted in weight loss and fostering support for healthy lifestyle among male peers. In addition to professionally created peer support groups, many online weight loss communities are created and moderated by peers. Online communities allow participants to share peer support similar to in-person formats.

Summary Many peer support interventions show significant short-term weight loss. Group members frequently report that peer support was critical to their weight loss success. A sense of community among likeminded individuals with similar goals was frequently cited. Online peer support groups are becoming increasingly prevalent, may fulfill similar needs to in-person groups, and have additional advantages in accessibility, and access to a larger peer network, and may facilitate long-term adherence.
\end{abstract}

Keywords Peer support $\cdot$ Weight loss $\cdot$ Weight loss maintenance $\cdot$ Online support

\section{Introduction: Challenges of Commercial Weight Loss Programs}

Obesity is a serious growing health concern. In 2017-2018, $42.4 \%$ of American adults were obese [1]. Because of the well-known ill health associated with obesity [2] including greater risk of cardiovascular disease [3], many obese individuals enroll in weight loss programs to improve their health. Unfortunately, very few individuals successfully lose weight: Men with a BMI $\geq 45$ have a 1 in 5 chance of losing 5\% body weight, while women ( 1 in 6 to10 chance) or men with a BMI 30-44.9 face even greater odds ( 1 in 8 to 12 chance) [4]. Even for those who defy the odds, long-term weight loss maintenance is difficult. A meta-analysis of studies examining

This article is part of the Topical Collection on Obesity and Diet

Kelsey Ufholz

keu8@ case.edu

1 Department of Family Medicine and Community Health, Case Western Reserve University, 11100 Euclid Avenue, Suite 1056, Cleveland, OH 44106, USA weight loss among American adults enrolled in structured weight loss programs with at least 2 years of follow-up data found that 5 years post weight loss, only $23.4 \%$ of initial weight loss was maintained [5].

A systematic review of commercial weight loss programs found only slightly greater weight loss compared with control or education-only comparison groups. Results ranged from 0.1 greater weight loss at 12 months for Atkins to $4.0 \%$ greater weight loss at 3-6 months, with attenuated effects thereafter, for very low calorie programs such as Medifast [6]. One explanation for both lack of initial weight loss and maintenance is unsustainability. Most trials reviewed lasted about 12 weeks and showed high attrition [6]. A meta-analysis of similar commercial weight loss programs, such as Weight Watchers and Biggest Losers Club, found that the majority of participants who began these programs (57\%) lost less than $5 \%$ of their body weight. Almost half of all studies (49\%) reported attrition rates $\geq 30 \%$ [7]. Conversely, longer term involvement was associated with greater success. For example, among Jenny Craig platinum program members, participants who remained in the program for 40-52 weeks lost $12.0 \%$ (SD $7.2 \%$ ) body weight, while those who left after $1-4$ weeks lost 
$1.1 \%$ (SD $1.6 \%$ ) body weight. Unfortunately, only $6.6 \%$ of original enrollees were still in the program by week 52 , with a full $27 \%$ dropping out within the first month [8]. Overall, long-term weight loss is especially difficult often because those seeking to lose weight discontinue their efforts.

We know that social support can enhance the effectiveness of structured weight loss programs. Despite obstacles, some formerly overweight individuals do manage to successfully lose weight and maintain weight loss. An often-cited review by Elfhag and Rossner found that these individuals had several strategies in common, including increased support from their social network [9]. The beneficial role of social support during weight loss and maintenance is well verified. Participants who were recruited to a weight loss program with a friend or family member lost more weight at 4 months, maintained the weight loss at 10 months, and showed lower rates of attrition compared with participants recruited to a standard weight loss program without any accompanying social support [10]. A recent meta-analysis of factors associated with greater adherence to a weight loss program identified the positive impact of social support (RR 1.29; 95\% CI 1.241.34) [11]. Yet, while the support of loved ones can be crucial and individuals maintaining recent weight loss cite support from family as especially important and wanted, they also cited these same people as obstacles, for example, tempting them with foods which do not fit within their diet [12], possibly because they are not experiencing the same process. This explains why during focus groups about what they found most helpful in their weight loss journey, women maintaining recent weight loss listed a sense of shared community among their peers [12].

Many health behavior change theories incorporate social support as an active change element. Social cognitive theory $[13,14]$ is a behavior change theory often employed in the context of socially supported weight loss (see Table 1). Interventions guided by this model teach behavioral modification techniques such as goal setting and self-monitoring. The peer support format allows members to provide positive reinforcement for success, helping them to build self-efficacy. Peer coaches and successful members may model successful behavior change, allowing for observational learning by less advanced members. Self-determination theory is an alternate theory that may be incorporated into successful peer support weight loss programs [15]. For example, skill-building and educational components can increase participants' sense of competence, or ability to complete tasks and achieve goals, while the support provided by peers will build a sense of relatedness or sense of being valued and cared for by others. Some interventions utilize theories, such as cognitive behavioral theory, that are traditionally associated with individuallevel psychotherapy rather than groups [16] with the addition of peer support components [17]. Such interventions often have peer support as an adjunct rather than as the primary active component. Other interventions are based not upon theoretical models but upon prior successful interventions for other conditions such as diabetes [18].

\section{How Peer Support Groups Function}

Peer support is defined as "the provision of emotional, appraisal, and informational assistance by a created social network member who processes experiential knowledge of a specific behavior or stressor and similar characteristics as the target population" [19]. A peer support group is a group of similar individuals who, because of shared experience, are able to provide emotional and practical support.

Peer support groups facilitate weight loss among their members through several mechanisms. Overweight individuals may have weak structural support, which refers to the extent to which a person is embedded into their social groups, including family, friends, and peer groups [12]. Overweight has been associated with the absence of close friends [20] both among adults and adolescents [21]. This may be partly due to bias. While overweight youth select possible friends without regard to BMI, healthy weight youth were $30 \%$ more likely to choose a nonoverweight friend rather than an overweight friend [22]. For individuals with limited social networks, peer support groups may be necessary to provide otherwise lacking structural support.

Peer support groups also provide members with functional support, which refers to specific actions that peers may perform for each other, such as providing emotional support or helpful information. Focus groups have found that such forms of support are highly desired, with shared community and increased self-efficacy, both forms of functional support, perceived as most helpful to weight loss maintenance [12]. Peer support groups need not meet in person to provide functional support. The Social Support Behavior Code lists five types of social support: informational support, such as providing facts, advice, and alternative perspectives upon situations; esteem support, such as compliments and validating other's experiences; network support, such as offering to spend time with others or providing access to resources; tangible support, such as offering the loan of something needed or to jointly complete a task; and emotional support, such as displays of empathy, sympathy, and encouragement [23, 24••]. An analysis of comments made in an online support forum for bariatric surgery patients noted that, although support which could be offered solely through anonymous written/verbal means, such as dietary advice (informational support) and encouragement (emotional support) were most frequently offered, network and tangible support were still present [24••]. Peer groups also create social norms, defined as a social group's expectation of appropriate behavior in a given circumstances [25, 26]. Social norms have long been known to influence eating behavior [27], both in healthy and unhealthy ways. A systematic review 


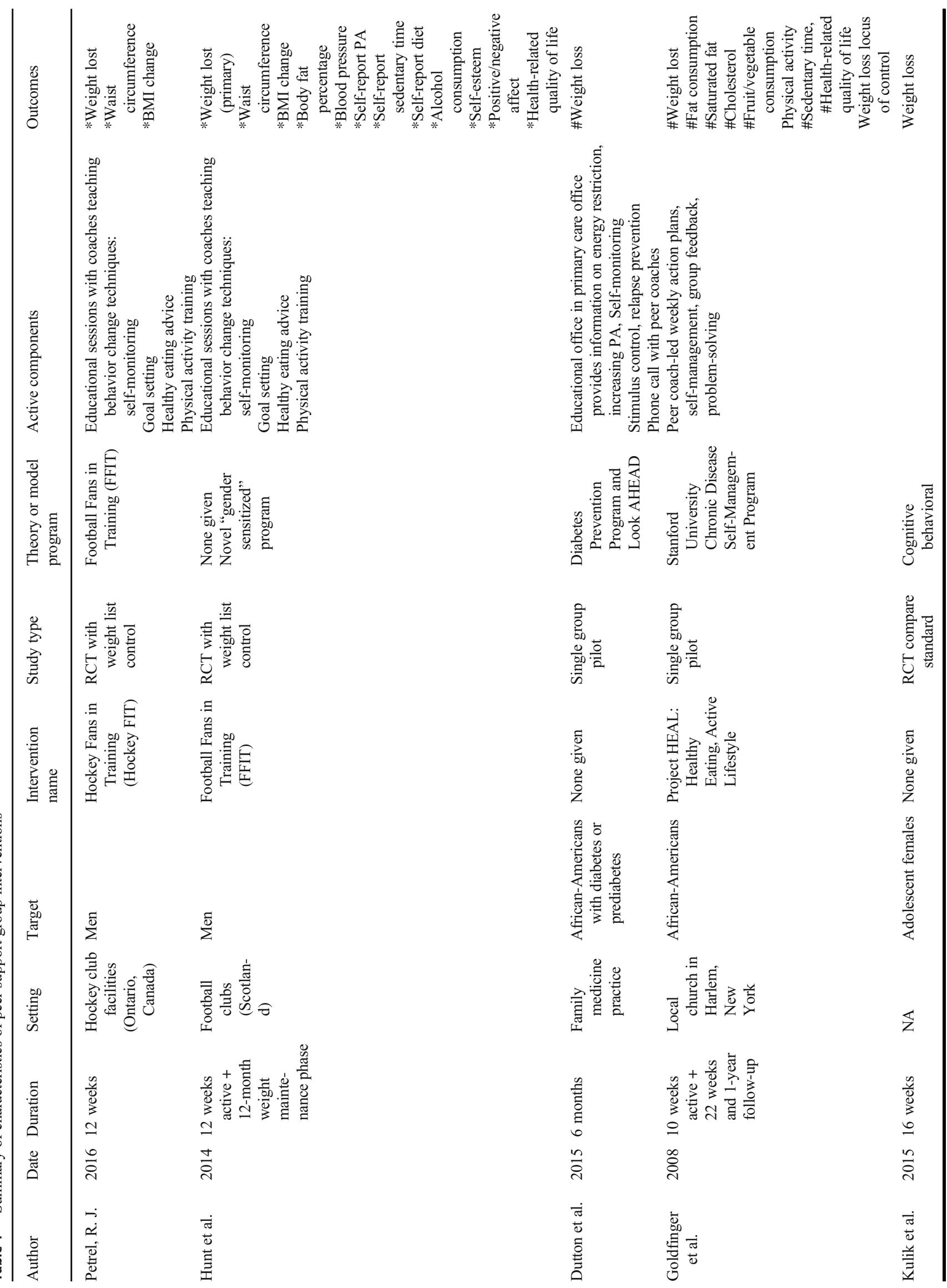




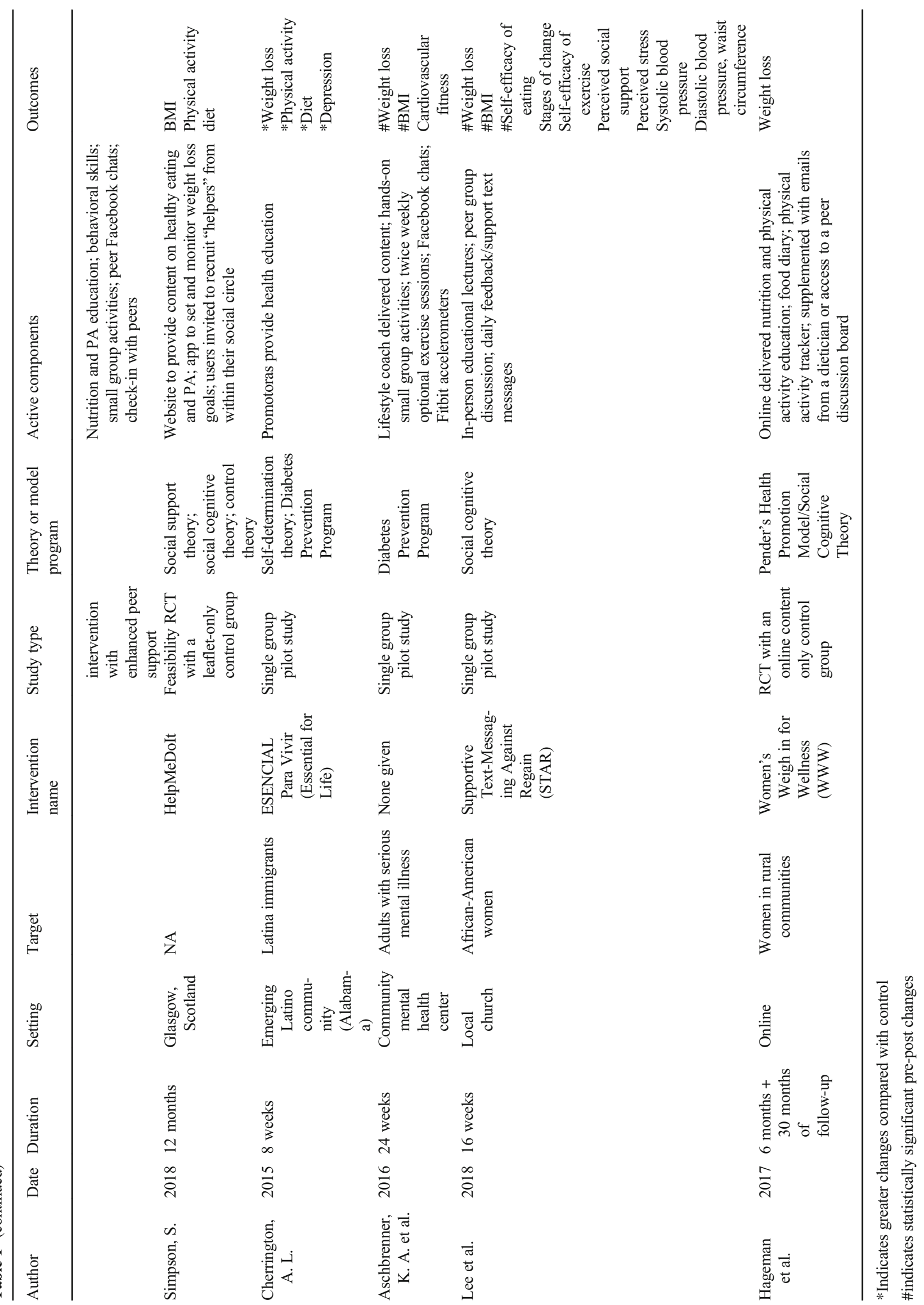


and meta-analysis found that both high-intake norms (standardized mean difference $=0.41 ; 95 \%$ CI 0.20 to $0.63 ; p<0.0001$ ) and low-intake norms (standardized mean difference $=-0.35$; $95 \% \mathrm{CI}-0.59$ to $-0.10 ; p=0.005)$ moderately influenced amount of food eaten [28]. Peer support groups, especially those with access to weight loss professionals, may be important to create healthy alternate norms among members.

The focus in this review is on the impact of peer support interventions. Usually, the primary outcome is weight lost, in absolute terms or as a body weight percentage. Successful peer support groups targeted at weight loss may also impact comorbidities commonly associated with obesity, with varying degrees of success. A recent meta-analysis of 26 randomized controlled trials found that compared with control, peer support interventions for weight loss led to improved glycemic control, $(\mathrm{HbA} 1 \mathrm{c}=-0.22 \%$; $95 \% \mathrm{CI}-0.40$ to $-0.04 ; p=0.02)$ and decreased obesity $\left(\mathrm{BMI}=-0.83 \mathrm{~kg} / \mathrm{m}^{2} ; 95 \% \mathrm{CI}-1.58\right.$ to -0.07 ; $p=0.03$ ), but had no significant effect upon systolic blood pressure $(-0.90 \mathrm{mmHG} ; 95 \% \mathrm{CI}-3.05$ to $1.24 \mathrm{mmHG})$. The authors speculate that high levels of attrition and selection bias may have influenced results [29]. Commercial weight loss programs not intended to improve diabetes or other cardiovascular risks may nevertheless have a desirable effect on these conditions. A randomized controlled trial found that participants enrolled in Weight Watchers showed greater improvements in both weight loss (difference $=3.3 \%$ body weight at 18 months; $p \leq 0.008$ ) (difference $=1.7 \%$ body weight at 24 months; $p \leq 0.032$ ) and HbAlc (difference $=1.0$ at 18 and 24 months; $p \leq 0.04$ ) compared with those assigned to a self-directed program created by the National Diabetes Education Program. Furthermore, both groups showed similar improvements in cardiovascular risk factors, including HDL cholesterol, diastolic, and systolic blood pressure [30]. Whether interventions for obesity-related comorbidities will also impact BMI remains uncertain. A separate meta-analysis found that peer support interventions for diabetes management improved systolic blood pressure $(2.07 \mathrm{mmHG}$; 95\% CI 0.35 to $3.79 \mathrm{mmHG} ; p=0.02$ ), but not diastolic blood pressure, cholesterol, BMI, diet, or physical activity. Because the selected studies focused upon diabetic control, cardiovascular risk factors, including BMI, were secondary outcomes and participants in most studies had only normal or mildly elevated values [31]. Overall peer support groups aimed at weight management can, but will not necessarily, also improve symptoms of obesity-related comorbidities.

\section{Common Traits of Peer Support Groups}

A search using the terms "peer support," "peer support group," "weight loss," and related terms in various combinations was carried out in PubMed, Google Scholar, etc., to identify papers published in 2015 and later. Approximately 70 relevant papers were ultimately reviewed. Peer support groups for weight loss showed several similarities. Much like other weight loss programs, results tended to be mixed, with members showing short-term results followed by later weight regain [32]. Occasionally, comparisons of peer support interventions with control groups that did not explicitly feature peer support, showed no difference between groups [33]. Sometimes, this may have been because participants did not utilize the peer support features, especially if these features were an adjunct to a traditional weight loss program [32]. Many peer support groups did not require attendance, but allowed participants to attend or not attend according to their interest or availability, although greater attendance was often associated with improved outcomes. For example, a peer support group for patients following bariatric surgery showed that the number of sessions attended in the first year was related to weight lost in the first year. Similar results were found for number of sessions attended 2-5 years post-surgery [34].

Many groups deliberately cultivated a sense of community among their members by selectively recruiting from high-risk groups. Often, these groups were a minority group or population who are traditionally difficult to reach with mainstream weight loss programs. For example, the STAR project was a feasibility pre-post study of a peer support group for AfricanAmerican women [35], an ethnic group with higher rates of obesity than many other ethnic groups [36]. Following 16 weeks of biweekly in-person peer group session and daily text messages, the women noted modest $(-3.7$ lbs.; $\mathrm{SD}=$ 3.5 lbs.) but statistically significant $(p<0.01)$ weight loss and decreased BMI $\left(-0.6 \mathrm{~kg} / \mathrm{m}^{2} ; \mathrm{SD}=0.6 \mathrm{~kg} / \mathrm{m}^{2} ; p=\right.$ 0.001) [35]. Similarly, Project HEAL, a pilot study of a church-based peer support group for African-Americans living in Harlem, New York, showed that participants lost $4.4 \mathrm{lbs}$. at 10 weeks $(p<0.01), 8.4 \mathrm{lbs}$. at 22 weeks $(p=$ $0.003)$, and $9.8 \mathrm{lbs}$. after 1 year $(p=0.001)$ and reported decreased fat consumption ( -7.6 daily fat intake in grams at 10 weeks; $p=0.46)(-4.0$ daily fat intake in grams at 22 weeks; $p=0.27)$ and sedentary time $(-1.3 \mathrm{~h} /$ day at 10 week; $p=0.34)(-2.9 \mathrm{~h} /$ day at 1 year; $p<0.01)$. Daily servings of fruit and vegetables also showed a modest $(0.7$ servings/day) but statistically significant increase at 22 weeks $(p=0.041)$ and 1 year $(p=0.039)$ [37]. Another pilot weight loss intervention enrolled African-Americans who presented with obesity and at least one cardiovascular risk, such as elevated blood pressure or A1C. Participants were recruited through a primary care practice and received biweekly visits with healthcare professionals, along with phone calls from peer coaches. After 6 months, participants lost an average of $4.5 \mathrm{~kg}$ and $27 \%$ lost $>5 \%$ of their body weight [18]. What these three interventions have in common is that they were tailored to the unique cultural needs of the African-American population. Two out of three were based in or recruited through churches and all actively recruited local community leaders who worked alongside healthcare educators. 
In addition to ethnic minorities, other high-risk groups, such as patients with serious mental illness, may benefit from peer support groups. Individuals with serious mental illness, such as schizophrenia or bipolar disorder, have rates of overweight/obesity exceeding $80 \%$ [38], and this group often struggles with finding adequate social support [39]. PeerFIT was a 24-week peer group intervention for individual with serious mental illness. The program consisted of weekly inperson sessions lead by lifestyle coaches, optional twice weekly group exercise sessions lead by fitness instructors from the local YMCA, physical activity tracking with FitBit accelerometers, program-related text messages, and peer-topeer support on social media. Post-intervention results showed that participants lost an average of $7.76 \mathrm{lbs}$. (SD = $12.4 \mathrm{lbs}$; $p=$ $0.005)$ and decreased their BMI significantly $\left(-1.25 \mathrm{~kg} / \mathrm{m}^{2}\right.$, $\left.\mathrm{SD}=1.99 \mathrm{~kg} / \mathrm{m}^{2} ; p=0.005\right)$, with $28 \%$ achieving clinically significant weight loss of $\geq 5 \%$ body weight [40]. Consistent with other peer support groups, members perceived a sense of community, with shared goals among individuals facing the same challenges, who could give and receive advice unique to their common goals, as essential to their success [41]. Perceived social support was found to be positively associated with weight loss $(r=0.59 ; p=0.002)$ [40॰], further highlighting its importance.

Often community-based interventions make use of peer coaches, defined as "individuals who participate in some capacity in health promotion but have no formal professional health care training and have an existing relationship or other connection with the community or population receiving care" [18]. One example is ESENCIAL Para Vivir (Essential for Life), a peer support intervention designed for Latina immigrants, another ethnic group with disproportionately high rates of obesity [36]. This peer support intervention was delivered by peer coaches known as "promotoras." Compared with data from a historical control group, after 8 weeks, participants showed significant weight loss $(-2.1 \mathrm{~kg} ; \mathrm{SD}=2.6 \mathrm{~kg} ; p<0.001)$ although this attenuated at 6 months $(p=0.67)$. Participants also showed improved dietary habits as measured by the Dietary Behavioral Strategies Scale $(p<0.001)$ and increased self-reported physical activity, as measured by the Global Physical Activity Questionnaire (47.1-min increase at 8 weeks; $p=0.004$ ) (54.3min increase at 6 months; $p=0.026$ ) [17]. During postintervention focus groups, participants stated a desire for culturally sensitive programs which incorporated traditional foods and customs, practical tips for physical activity, and involved family members, especially husbands [17].

\section{Peer Group Weight Loss Interventions for Men}

Obesity rates among adult men $(34.3 \%$; $95 \%$ CI $32.6-36.1)$ and women $(38.3 \%$; $95 \%$ CI $36.1-40.5)$ are both worryingly high [36]. Yet, many weight loss interventions are designed solely for women. Even in interventions not designed exclusively for women, the majority of participants tend to be women. Only $5 \%$ of weight loss trials utilize all-male samples, while $32 \%$ utilize an all-female sample; $27 \%$ of all weight loss intervention participants are men, and only $1.8 \%$ are men of an ethnic minority [42]. While men may need weight loss interventions, such interventions do not appeal to them.

Semi-structured interviews of men's experience in weight loss interventions found that men perceived behaviors such as dieting and self-monitoring weight as feminine. Men who attended commercial weight loss programs reported feeling uncomfortable, ostracized, and that the program was better suited to women [43]. A series of focus groups among men in southwest England gathered their perspectives on diet, physical activity, and weight loss behaviors. It was found that these men regarded dieting, counting calories, and commercial weight loss groups as a "women's thing," of no interest to "proper blokes." Physical activity was more socially acceptable, especially in a sporting context. Few men reported receiving peer support for weight loss from friends. In contrast, family, especially wives and girlfriends, were seen as supportive and knowledgeable about nutrition [44]. Collectively, these results highlight a need for weight loss interventions focused on men's concerns, especially ones which cultivate peer support for dieting, physical activity, weight monitoring, etc. from other men.

Several recent weight loss programs have been designed exclusively for men, taking advantage of already existing male-oriented groups. One example is Football Fans in Training (FFIT), an intervention for members of a Scottish professional football club (soccer fan group). FFIT combined educational content, such as how to self-monitor and set specific goals, with supervised physical activity. Early intervention sessions emphasized the educational components, while later sessions focused more upon physical activity. The program was designed to tap into a pre-existing community and "work with rather than against prevailing understandings of masculinity." The intervention was overseen by community football coaches who had been trained by the research staff and took place at the club's home stadium [45]. Compared with a wait-list control group who only received a weight management book, the intervention group showed significant changes in BMI $\left(-1.66 \mathrm{~kg} / \mathrm{m}^{2} ; 95 \% \mathrm{CI}-1.93\right.$ to $-1.40 \mathrm{~kg} / \mathrm{m}^{2}$ at 12 weeks; $p<0.0001)\left(-1.56 \mathrm{~kg} / \mathrm{m}^{2} ; 95 \% \mathrm{CI}-1.82\right.$ to $-1.29 \mathrm{~kg} / \mathrm{m}^{2}$ at 12 months; $\left.p<0.0001\right)$, waist circumference $(-5.57 \mathrm{~cm} ; 95 \% \mathrm{CI}-6.41$ to $-4.72 \mathrm{~cm}$ at 12 weeks $p<0.0001)(-5.12 \mathrm{~cm} ; 95 \% \mathrm{CI}-5.97$ to $-4.27 \mathrm{~cm}$ at 12 months; $p<0.0001)$, body fat percentage $(-2.16 \%$; $95 \%$ CI -2.81 to -1.51 at 12 weeks; $p<0.0001)(-2.15 \% ; 95 \%$ $\mathrm{CI}-2.78$ to $-1.52 \%$ at 12 months; $p<0.0001$ ), as well as improvements in self-reported physical activity in METminutes/week $($ median $=2.38$; IQR 1.90 to 2.98 at 12 weeks; 
$p<0.0001)($ median $=1.49$, IQR 1.11 to 1.98 at 12 months; $p=0.008$ ), healthy diet as measured by Dietary Instrument for Nutrition Education scores for fatty foods $(-4.39 ; 95 \%$ CI -5.16 to $-3.61 ; p<0.0001$ at 12 weeks $)(-2.74 ; 95 \%$ CI -3.52 to $-1.96 ; p<0.0001$ at 12 months), fruit and vegetable consumption $(1.32 ; 95 \%$ CI 1.07 to $1.57 ; p<0.0001$ at 12 weeks) $(0.54 ; 95 \%$ CI 0.29 to $0.79 ; p<0.0001$ at 12 months $)$, sugary foods $(-1.52 ; 95 \% \mathrm{CI}-1.83$ to $1.21 ; p<0.0001$ at 12 weeks) $(-0.87 ; 95 \% \mathrm{CI}-1.18$ to $-0.56 ; p<0.0001$ at 12 months), and alcohol consumption ( -4.47 units/week; $95 \% \mathrm{CI}-6.09$ to $-2.86 ; p<0.001$ at 12 weeks) $(-2.59$ units/ week; 95\% CI -4.21 to $-0.97 ; p<0.0017$ at 12 months) [46]. During focus groups, participants expressed appreciation for a community of men with similar interests and facing similar challenges. Such a context allowed them to discuss weightrelated challenges without worrying about challenges to their masculinity [47]. Weight loss programs such as this can and have been adapted to other sporting contexts. Hockey FIT, developed for Canadian hockey fans, followed the same format as FFIT and showed similar results. Compared with a wait-list control, after 12 weeks, those who received Hockey FIT showed reductions in waist circumference $(-2.8 \mathrm{~cm} ; 95 \%$ CI -5.0 to $-0.6 \mathrm{~cm} ; p=0.01)$ and BMI $\left(-0.9 \mathrm{~kg} / \mathrm{m}^{2} ; 95 \%\right.$ $\mathrm{CI}-1.4$ to $\left.-0.4 \mathrm{~kg} / \mathrm{m}^{2} ; p<0.001\right)[45,48 \cdot]$. Post-intervention, $100 \%$ of participants reported healthier diet and $78 \%$ reported increased physical activity. Critically, many of them cited receiving support from their coaches and fellow participants as critical for their success and found it helpful that they were part of a community of like-minded people, reinforcing a consistent theme among peer support groups for weight loss [48•].

\section{Online Peer Support}

While many peer support groups consist of small groups meeting in person, other formats have advantages (see Table 2). Online weight loss communities have become popular over the past 10 years. These websites often include features such as chat rooms, blogs, and discussion forums. In-person peer support groups often encounter practical barriers, such as geographic distance and difficulty finding transportation to in-person events. Online formats, unlike in-person support groups, are also untethered to specific times or dates. In-person peer groups have a tacit expectation of reciprocal support, in contrast to online peer groups in which pleas for assistance may be borne by the group as a whole [49]. Internet peer support group members endorsed preference for the Internet community because they liked the anonymity, which allowed greater freedom to discuss more sensitive topics, and found the interactions to be non-judgmental, especially compared with people in their lives such as friends and family members [50].

Individuals who chose online peer support groups may have different needs compared with those who utilize inperson support groups. A survey of users of online healthrelated social groups found that these individuals were dissatisfied with the support they received from their in-person network [49]. Members of online peer support communities may $\log$ into those communities whenever they feel in need of extra validation or support. Such a format allows members to customize their level of engagement.

Despite the different format, the active change elements of online peer support groups may be quite similar to those present in in-person peer groups. Surveys of members of SparkPeople, an Internet weight loss community, stated that in the past 4 weeks, they had at least once a day read weightrelated messages on discussion forums (56.8\%), replied to messages on forums $(36.1 \%)$, and started weight-related discussions (18.5\%) [50]. Even more so, members of these communities said they received encouragement, motivation, recognition for success, accountability to a shared community, humor, and information [50]. In other words, support offered by the online community mirrored support offered by inperson peer groups. Similarly, an examination of messages posted on a forum of a large online bariatric surgery discussion website found that the majority of messages aimed at

Table 2 A comparison of in-person and online peer support groups

\begin{tabular}{|c|c|c|}
\hline & Pros & Cons \\
\hline In-person & $\begin{array}{l}\text { - Sense of community may be enhanced by person-to-person communication } \\
\text { - Members may complete physical activity together, with a professional trainer } \\
\text { - Skill-building activities, such as cooking classes, can be conducted in person } \\
\text { - Group facilitators can monitor suggestions offered for accuracy } \\
\text { - May have greater retention }\end{array}$ & $\begin{array}{l}\text { - Outspoken members may dominate } \\
\text { conversation } \\
\text { - Group is limited to specific time and } \\
\text { place } \\
\text { - May be difficult for socially anxious }\end{array}$ \\
\hline Online & $\begin{array}{l}\text { - Ability to recruit special populations that cannot assemble enough individuals for an in-person } \\
\text { group (bariatric patients, individuals with mental illness) } \\
\text { - Members can access support without time or geographic restrictions } \\
\text { - Access to larger peer support group } \\
\text { - Cost-effective compared with in-person } \\
\text { - May have greater long-term sustainability } \\
\text { - Members can log in whenever it is convenient or they need extra support }\end{array}$ & $\begin{array}{l}\text { Difficult to provide non-verbal, } \\
\text { tangible support } \\
\text { - Unmonitored sites can promote } \\
\text { unhealthy social norms }\end{array}$ \\
\hline
\end{tabular}


both those who were preparing for surgery and those who were adjusting to post-surgical life included emotional support, such as expressions of encouragement and sympathy following setbacks, and instrumental support, such as recommendations on specific foods and reappraising frustrating situations with family in a more positive manner [24••].

Some individuals choose online weight loss options as part of a self-directed weight loss journey rather than seeking professional help. However, just as professionally led in-person weight loss interventions often involve peer support as part of their method, online peer support groups are now being integrated into both in-person and online weight loss interventions. An example of an online-only weight loss program which includes peer support is Noom. Program features include logging into an mHealth application ("app") where members may share food logs, weight loss goals, and challenges. Results found that receiving peer support did not directly predict weight loss $(p=0.08)$, but peer support did predict increases in food logging among participation (path coefficient $=0.45, p<0.05$ ), which then predicted weight loss (path coefficient $=0.37, p<0.05)$ [51].

Social media is a popular venue for member-created peer support groups. Such venues have several unique features. As of February 2019, 73\% of American adults have used YouTube and $69 \%$ have used Facebook, with many reporting that they access social media platforms daily [52], suggesting access to a very large peer support group. The level of anonymity and detail varies based on media platform. Comparisons of two branches of an online weight loss program, one with an online discussion board and one with access to a Facebook community, found that individuals who utilized Facebook reported greater emotional support compared with those who used the online discussion forum (1.0 point difference, $p<0.05)$. The authors speculated that these effects may derive from differences in the nature of these media, in which Facebook social support may be traced to specific individuals via their detailed profiles, in contrast to anonymous discussion posts. Noteworthy, active (5-6\% body weight) and non-active ( $6.1 \%$ body weight) users of the online program showed similar weight loss results at 6 weeks $(p>0.108)$. Active users were more satisfied with the program $(0.3-0.7$ point difference), reported greater compliance ( $0.3-1.0$ point difference), more perceived success $(0.1-0.8$ point difference), and greater emotional (1.0-2.3 point difference), informational (1.1-2.4 point difference), and instrumental support (0.1-1.2 point difference) ( $p<0.05$, all differences), which may translate into more sustained usage and greater success long term [53].

There may be limits to what can be achieved via online support. A web-based weight loss program for rural women supplemented with an online peer-led discussion blog was found to result in modest weight loss (4.0-5.8 kg at 6 months). However, the weight lost was no greater compared with the program without the peer support blog $(0.9 \mathrm{~kg} ; 95 \% \mathrm{CI}-0.8$ to $2.7 \mathrm{~kg}$ at 6 months; $p=0.36)$ or compared with a program supplemented by emails from a professional counselor $(-1.7 \mathrm{~kg} ; 95 \% \mathrm{CI}-3.4$ to $0.0 \mathrm{~kg}$ at 6 months; $p=0.56)$. Only about half $(45 \%)$ the women with access to the peer-led discussion blog used it in the first 6 months of the study, and this percentage dropped further $(22 \%)$ over the course of the study. The authors speculated that participants may have never felt like they were part of a community, essentially making their intervention the same as the control group [32] and once again highlighting the importance of shared community for the success of peer support groups.

\section{Practical Recommendations on Fostering Shared Community}

A consistent theme among peer support groups is the need for a sense of shared community among members. This may be achieved through several overlapping methods. To foster a sense of relatedness, so that members feel heard and valued, all members should be given a chance to share and express opinions at each meeting. Members may be encouraged to offer varied types of functional support, including emotional support, informational support, and when possible tangible support. Community may already exist if group members are recruited from already existing groups, such as members of the same church or employees at the same office. Facilitators who share similar characteristics as group members or advanced group members who transition into facilitator roles may be perceived as more relatable and credible.

Some peer support groups incorporate hand-on educational activities such as cooking classes. Such activities may, in addition to practical skills, give participants a sense of working towards a common goal such as a shared meal. Group exercise classes have the added benefits of friendly competition, fun, and a break from monotony. Peers may actively support one another such as holding a peer's feet during sit-ups and cheering encouragement while jogging. Group exercises may be particularly beneficial in community building for male participants, who tend to incline towards physical activity [44], and for quieter group members who may not engage as often in group conversations. Ideally, exercise classes will include aerobic, strength-based, and stretching exercises. To ensure safety, supervision by a professional fitness instructor is highly recommended.

Virtual support groups, especially those which operate solely online, have special challenges creating community and connectedness. Online support groups tend to be more successful when participants feel seen as unique individuals and have enough knowledge about their fellow group members to also see them as unique individuals [53]. Smaller groups allow greater time for each member to speak. Use of both visual and audio during meetings may help foster connection. Group activities may be possible online if they make use of minimal, commonly available equipment. 


\section{Conclusion: Future of Peer Support Interventions}

Weight loss interventions need to be more than just effective at helping participants lose weight in the short term. A truly successful program must support behavior change that can be maintained over years rather than weeks. To maintain this sustainability, the program must be cost-effective enough that participants can maintain membership long term and must be able to occasionally reengage in an on-going group when necessary [54]. Peer support groups may help fulfill this function.

Pre-existing online forums may represent a natural medium for peer support groups, and such venues have several advantages, not the least of which is their accessibility from any location. Thus far, social media has largely served as a supplement to other active elements within weight loss programs, such as group educational content or counseling; comparatively, little is known about social media's independent effect within these programs [55॰]. Given social media's ubiquity and popularity, there is great potential there; with social media's well-known ability to propagate misinformation $[56,57]$ and harmful norms [58], guidance from healthcare professionals or trained peer coaches may be necessary safeguards.

To summarize, peer-led support groups represent a novel and potentially effective form of weight loss interventions, especially when the intervention successfully creates a sense of shared community among its members. Peer support groups appear to be particularly effective in supporting vulnerable at-risk populations, such as ethnic minorities. The utility of online peer support as an adjunct to in-person peer support may not greatly improve short-term study outcomes but is positively perceived by participants and may improve long-term adherence.

\section{Compliance with Ethical Standards}

Conflict of Interest Kelsey Ufholz declares she has no conflicts of interest.

Human and Animal Rights and Informed Consent This study does not contain any studies with human or animal subjects performed by the author.

Open Access This article is licensed under a Creative Commons Attribution 4.0 International License, which permits use, sharing, adaptation, distribution and reproduction in any medium or format, as long as you give appropriate credit to the original author(s) and the source, provide a link to the Creative Commons licence, and indicate if changes were made. The images or other third party material in this article are included in the article's Creative Commons licence, unless indicated otherwise in a credit line to the material. If material is not included in the article's Creative Commons licence and your intended use is not permitted by statutory regulation or exceeds the permitted use, you will need to obtain permission directly from the copyright holder. To view a copy of this licence, visit http://creativecommons.org/licenses/by/4.0/.

\section{References}

Papers of particular interest, published recently, have been highlighted as:

- Of importance

- Of major importance

1. Hales CM, Carroll MD, Fryar CD, Ogden CL. Prevalence of obesity and severe obesity among adults: United States, 2017-2018. NCHS Data Brief, no 360. Hyattsville, MD: National Center for Health Statistics. 2020.

2. Abdelaal M, le Roux CW, Docherty NG. Morbidity and mortality associated with obesity. Ann Transl Med. 2017;5(7).

3. Leggio M, Lombardi M, Caldarone E, Severi P, D'emidio S, Armeni M, et al. The relationship between obesity and hypertension: an updated comprehensive overview on vicious twins. Hypertens Res. 2017;40(12):947-63.

4. Fildes A, Charlton J, Rudisill C, Littlejohns P, Prevost AT, Gulliford MC. Probability of an obese person attaining normal body weight: cohort study using electronic health records. Am J Public Health. 2015;105(9):e54-e9.

5. Anderson JW, Konz EC, Frederich RC, Wood CL. Long-term weight-loss maintenance: a meta-analysis of US studies. Am J Clin Nutr. 2001;74(5):579-84.

6. Gudzune KA, Doshi RS, Mehta AK, Chaudhry ZW, Jacobs DK, Vakil RM, et al. Efficacy of commercial weight-loss programs: an updated systematic review. Ann Intern Med. 2015;162(7):501-12.

7. McEvedy SM, Sullivan-Mort G, McLean SA, Pascoe MC, Paxton SJ. Ineffectiveness of commercial weight-loss programs for achieving modest but meaningful weight loss: systematic review and meta-analysis. J Health Psychol. 2017;22(12):1614-27.

8. Finley C, Barlow C, Greenway F, Rock C, Rolls BJ, Blair SN. Retention rates and weight loss in a commercial weight loss program. Int J Obes. 2007;31(2):292-8.

9. Elfhag K, Rössner S. Who succeeds in maintaining weight loss? A conceptual review of factors associated with weight loss maintenance and weight regain. Obes Rev. 2005;6(1):67-85.

10. Wing RR, Jeffery RW. Benefits of recruiting participants with friends and increasing social support for weight loss and maintenance. J Consult Clin Psychol. 1999;67(1):132-8.

11. Lemstra M, Bird Y, Nwankwo C, Rogers M, Moraros J. Weight loss intervention adherence and factors promoting adherence: a meta-analysis. Patient Prefer Adherence. 2016;10:1547.

12. Connor A, George G. Women's perceived and desired support for weight loss. J Fam Consum Sci. 2018;110(1):38-44.

13. Bandura A. Social cognitive theory of moral thought and action. Handbook of moral behavior and development: Psychology Press; 2014. p. 69-128.

14. Simpson S. The Helpmedoit! weight loss trial: main results. Int J Behav Med. 2018;25(S1).

15. Ryan RM, Deci EL. Intrinsic and extrinsic motivations: classic definitions and new directions. Contemp Educ Psychol. 2000;25(1):54-67.

16. Hupp S, Reitman D, Jewell JD. Cognitive-behavioral theory. Handb Clin Psychol. 2008;2:263-87.

17. Cherrington AL, Willig AL, Agne AA, Fowler MC, Dutton GR, Scarinci IC. Development of a theory-based, peer support intervention to promote weight loss among Latina immigrants. BMC Obes. 2015;2(1):17.

18. Dutton GR, Phillips JM, Kukkamalla M, Cherrington AL, Safford MM. Pilot study evaluating the feasibility and initial outcomes of a 
primary care weight loss intervention with peer coaches. Diabetes Educ. 2015;41(3):361-8.

19. Dennis C-L. Peer support within a health care context: a concept analysis. Int J Nurs Stud. 2003;40(3):321-32.

20. Sarlio-Lähteenkorva S, Lahelma E. The association of body mass index with social and economic disadvantage in women and men. Int J Epidemiol. 1999;28(3):445-9.

21. Strauss RS, Pollack HA. Social marginalization of overweight children. Arch Pediatr Adolesc Med. 2003;157(8):746-52.

22. Schaefer DR, Simpkins SD. Using social network analysis to clarify the role of obesity in selection of adolescent friends. Am J Public Health. 2014;104(7):1223-9.

23. Cutrona CE, Suhr JA. Controllability of stressful events and satisfaction with spouse support behaviors. Commun Res. 1992;19(2): 154-74.

24.• Atwood ME, Friedman A, Meisner BA, Cassin SE. The exchange of social support on online bariatric surgery discussion forums: a mixed-methods content analysis. Health Commun. 2018;33(5): 628-35 This manuscript provides a detailed descriptions of various forms of social support, including informational and emotional, and how they may be utilized in an online setting. An excellent primer for how social support manifests in both an online and offline enviroment.

25. Eldredge LKB, Markham CM, Ruiter RA, Fernández ME, Kok G, Parcel GS. Planning health promotion programs: an intervention mapping approach: Wiley; 2016.

26. Draper C, Grobler L, Micklesfield L, Norris S. Impact of social norms and social support on diet, physical activity and sedentary behaviour of adolescents: a scoping review. Child Care Health Dev. 2015;41(5):654-67.

27. Higgs S, Thomas J. Social influences on eating. Curr Opin Behav Sci. 2016;9:1-6.

28. Robinson E, Thomas J, Aveyard P, Higgs S. What everyone else is eating: a systematic review and meta-analysis of the effect of informational eating norms on eating behavior. J Acad Nutr Diet. 2014;114(3):414-29.

29. McEvoy C, McAuley E, Moore S, Cupples M, Kee F, Young I, et al. A systematic review and meta-analysis of the effectiveness of peer support to reduce cardiovascular risk. Proc Nutr Soc. 2017;76(OCE3).

30. Palmer KN, Saha C, Phillips E, Krishnan A, Foster GD, Finkelstein E, et al. The two-year outcomes and cost effectiveness of a commercial weight loss program for the prevention of type 2 diabetes among people with prediabetes. Endocrinol Diabetes Obes. 2018;1(1):5.

31. Patil SJ, Ruppar T, Koopman RJ, Lindbloom EJ, Elliott SG, Mehr $\mathrm{DR}$, et al. Effect of peer support interventions on cardiovascular disease risk factors in adults with diabetes: a systematic review and meta-analysis. BMC Public Health. 2018;18(1):398.

32. Hageman PA, Pullen CH, Hertzog M, Pozehl B, Eisenhauer C, Boeckner LS. Web-based interventions alone or supplemented with peer-led support or professional email counseling for weight loss and weight maintenance in women from rural communities: results of a clinical trial. J Obes. 2017;2017:1-21.

33. Kulik N, Ennett ST, Ward DS, Bowling JM, Fisher EB, Tate DF. Brief report: a randomized controlled trial examining peer support and behavioral weight loss treatment. J Adolesc. 2015;44:117-23.

34. Andreu A, Jimenez A, Vidal J, Ibarzabal A, De Hollanda A, Flores L, et al. Bariatric support groups predicts long-term weight loss. Obes Surg. 2020:1-6.

35. Lee S, Schorr E, Chi C-L, Treat-Jacobson D, Mathiason MA, Lindquist R. Peer group and text message-based weight-loss and management intervention for African American women. West $\mathrm{J}$ Nurs Res. 2018;40(8):1203-19.

36. Ogden CL, Fakhouri TH, Carroll MD, Hales CM, Fryar CD, Li X, et al. Prevalence of obesity among adults, by household income and education-United States, 2011-2014. MMWR Morb Mortal Wkly Rep. 2017;66(50):1369-73.

37. Goldfinger JZ, Arniella G, Wylie-Rosett J, Horowitz CR. Project HEAL: peer education leads to weight loss in Harlem. J Health Care Poor Underserved. 2008;19(1):180-92.

38. Correll CU, Druss BG, Lombardo I, O'Gorman C, Harnett JP, Sanders KN, et al. Findings of a US national cardiometabolic screening program among 10,084 psychiatric outpatients. Psychiatr Serv. 2010;61(9):892-8.

39. Kilbourne AM, McCarthy JF, Post EP, Welsh D, Blow FC. Social support among veterans with serious mental illness. Soc Psychiatry Psychiatr Epidemiol. 2007;42(8):639-46.

40. Aschbrenner KA, Naslund JA, Shevenell M, Kinney E, Bartels SJ. A pilot study of a peer-group lifestyle intervention enhanced with $\mathrm{mHealth}$ technology and social media for adults with serious mental illness. J Nerv Ment Dis. 2016;204(6):483 This manuscript provides a description of a peer support program, unique in its focus upon individuals with serious mental illness, and the comprehensiveness of the program described.

41. Aschbrenner KA, Naslund JA, Bartels SJ. A mixed methods study of peer-to-peer support in a group-based lifestyle intervention for adults with serious mental illness. Psychiatr Rehabil J. 2016;39(4): 328-34.

42. Pagoto SL, Schneider KL, Oleski JL, Luciani JM, Bodenlos JS, Whited MC. Male inclusion in randomized controlled trials of lifestyle weight loss interventions. Obesity. 2012;20(6):1234-9.

43. Sidhu M, Aiyegbusi O, Daley A, Jolly K. Older men's experience of weight loss and weight loss maintenance interventions: qualitative findings from the Lighten Up Plus Trial. J Obes Weight Loss Ther. 2016;1(003).

44. Harcourt KA, Appleton J, Clegg ME, Hunter L. The influence of social relationships on men's weight. J Nutr Educ Behav. 2020;52(2):106-13.

45. Petrella RJ, Gill DP, De Cruz A, Riggin B, Muise S, Pulford R, et al. Can a sports team-based lifestyle program (hockey fans in training) improve weight in overweight men?: 2140 Board\# 292 June 2, 330 PM-500 PM. Med Sci Sports Exerc. 2016;48(5S):604.

46. Hunt K, Wyke S, Gray CM, Anderson AS, Brady A, Bunn C, et al. A gender-sensitised weight loss and healthy living programme for overweight and obese men delivered by Scottish Premier League football clubs (FFIT): a pragmatic randomised controlled trial. Lancet. 2014;383(9924):1211-21.

47. Bunn C, Wyke S, Gray CM, Maclean A, Hunt K. 'Coz football is what we all have': masculinities, practice, performance and effervescence in a gender-sensitised weight-loss and healthy living programme for men. Sociol Health Illn. 2016;38(5):812-28.

48. Muise SB, Gill DP, De Cruz A, Riggin B, Pulford R, Sibbald SL, et al. Men's experiences with the hockey fans in training weight loss and healthy lifestyle program. Int J Med Stud. 2016;4(3):91-5 This qualitative study describes the active elements necessary for a successful weight loss intervention for men.

49. Chung JE. Social interaction in online support groups: preference for online social interaction over offline social interaction. Comput Hum Behav. 2013;29(4):1408-14.

50. Hwang KO, Ottenbacher AJ, Green AP, Cannon-Diehl MR, Richardson O, Bernstam EV, et al. Social support in an Internet weight loss community. Int J Med Inform. 2010;79(1):5-13.

51. Kim H, Faw M, Michaelides A. Mobile but connected: harnessing the power of self-efficacy and group support for weight loss success 
through mHealth intervention. J Health Commun. 2017;22(5):395402.

52. Perrin AA, Monica. Share of U.S. adults using social media, including Facebook, is mostly unchanged since 2018 Pew Research CenterApril 19, 2019 [Available from: https://www.pewresearch. org/fact-tank/2019/04/10/share-of-u-s-adults-using-social-mediaincluding-facebook-is-mostly-unchanged-since-2018/.

53. Taiminen H. How do online communities matter? Comparison between active and non-active participants in an online behavioral weight loss program. Comput Hum Behav. 2016;63:787-95.

54. Rao G, Kirley K. The future of obesity treatment: comment on "integrating technology into standard weight loss treatment: a randomized controlled trial”. JAMA Intern Med. 2013;173(2):111-2.

55. Dahl AA, Hales SB, Turner-McGrievy GM. Integrating social media into weight loss interventions. Curr Opin Psychol. 2016;9:11-5
This review article is essential reading for any researcher or clinician interested in inclusion of social media into a weight loss intervention.

56. Wang Y, McKee M, Torbica A, Stuckler D. Systematic literature review on the spread of health-related misinformation on social media. Soc Sci Med. 2019;240:112552.

57. Chou WYS, Oh A, Klein WM. Addressing health-related misinformation on social media. Jama. 2018;320(23):2417-8.

58. Ghaznavi J, Taylor LD. Bones, body parts, and sex appeal: an analysis of \#thinspiration images on popular social media. Body Image. 2015;14:54-61.

Publisher's Note Springer Nature remains neutral with regard to jurisdictional claims in published maps and institutional affiliations. 